\title{
Influência do peso ao início da terminação sobre as características de carcaça e da carne de novilhos mestiços Nelore $\times$ Charolês
}

\author{
Patrícia Alessandra Meneguzzi Metz ${ }^{1}$, Luís Fernando Glasenapp de Menezes ${ }^{2}$, Miguelangelo \\ Ziegler Arboitte ${ }^{2}$, Ivan Luiz Brondani ${ }^{3}$, João Restle ${ }^{4}$, Alisson Marian Callegaro ${ }^{5}$ \\ ${ }^{1}$ Curso de Zootecnia e Programa de Pós-Graduação do Departamento de Zootecnia - UFSM. Bolsista CNPq. Endereço: Rua Angelin \\ Bortholuzzi, 176, Camobi, Santa Maria - RS. \\ 2 Programa de Pós-Graduação do Departamento de Zootecnia - UFSM. \\ ${ }^{3}$ Departamento de Zootecnia - UFSM. \\ ${ }^{4}$ Professor Visitante - UFG. \\ ${ }^{5}$ Cursos de Medicina Veterinária e Zootecnia - UFSM. Bolsista FATEC/UFSM.
}

RESUMO - Foram utilizados 12 novilhos 5/8 Nelore 3/8 Charolês, com média de 22 meses de idade (660 dias). Na entrada do confinamento, os animais foram divididos em duas categorias, conforme a idade inicial ao confinamento: animais leves - peso vivo (PV) inicial de 362,67 kg; e animais pesados - peso vivo inicial de 441,83 kg. O peso de abate determinado para ambos os grupos foi de $500 \mathrm{~kg}$. Os animais foram alimentados com silagem de milho e concentrado (relação 60:40). Os pesos iniciais aumentaram o tempo de confinamento, uma vez que os animais leves permaneceram no confinamento 94 dias e os pesados, 30 dias. Os animais leves tiveram portes iniciais e finais menores e apresentaram carcaças com maior espessura de gordura. O costilhar foi o único corte comercial influenciado pelo peso inicial. Animais mais pesados ao início do confinamento apresentaram maior porcentagem de traseiro e menor de costilhar. A quantidade de músculo foi maior nos animais mais pesados. O menor peso inicial resultou em animais de menor porte e com menor altura de garupa, maior espessura de gordura na carcaça e no costilhar e menor quantidade de traseiro e músculo. As características da carne não foram influenciadas pelos pesos ao início do confinamento.

Palavras-chave: cortes comerciais, espessura de gordura, porte, tempo confinamento

\section{Different finishing initial weights on carcass and meat characteristics of Nellore $\times$ Charolais crossbred steers}

\begin{abstract}
Twelve 5/8 Nellore 3/8 Charolais steers were used, with 22 months (660 days) of age. The animals were feedlot finished and divided into two categories: light animals - initial feedlot live weight (LW) of $362.67 \mathrm{~kg}$ and heavy animals - initial feedlot LW of $441.33 \mathrm{~kg}$. The slaughter weight established was of $500 \mathrm{~kg}$. The animals were fed a 60:40 ratio corn silage and concentrate diet. The different initial weights at the finishing increased the feedlot time, since light animals were kept for 94 days and heavy animals for 30 days. Light animals had lower initial and final frames and showed higher fat thickness. The unique commercial cut that suffered influence from initial weights was sidecut. Heavy animals presented higher sawcut and lower quantity of sidecut. Heavy animals had higher muscle quantity. The lower initial weight generated animals with lower frame size and crupper height, carcasses with higher fat thickness and sidecut, lower sawcut and muscle quantity. Meat characteristics were not influenced by the different initial weights at finishing.
\end{abstract}

Key Words: commercial cuts, fat thickness, feedlot period, frame size, meat

\section{Introdução}

A bovinocultura brasileira tem se destacado mundialmente pelo grande volume de carne exportada (ANUALPEC, 2006), mas, para atingir este mercado externo, foi adaptada à realidade da bovinocultura mundial, mais modernizada. Com o objetivo de alcançar estes mercados, os frigoríficos brasileiros passaram a exigir carcaças com peso elevado, bom grau de acabamento e abate em idade inferior a 36 meses. Concomitantemente a esta situação, produtores são pressionados a produzir carcaças de alta qualidade na tentativa para atender às exigências dos frigoríficos e manter-se no mercado das exportações.

Vários problemas, como a não-padronização do rebanho, contribuem para que o produtor não obtenha níveis de produção adequados. Os rebanhos brasileiros, em sua 
maioria, possuem pouco melhoramento genético, grande diversidade de raças e animais com diversos pesos vivos em mesma idade, o que acarreta desuniformidade de carcaças. Produtores com rebanhos não padronizados e que utilizam técnicas modernas, como o confinamento para terminação dos animais, sofrem com a discrepância de tempo de confinamento entre animais submetidos à terminação com pesos diferentes. Animais de menor peso vivo demoram mais tempo para atingir a condição de abate e, segundo Di Marco (1998), aqueles com idade mais avançada caracterizam-se pelo maior custo energético para ganho de peso e acumulam maior quantidade de gordura corporal por menor consumo relativo, o que reduz a eficiência de transformação de alimento em ganho de peso. De acordo com esse autor, o tamanho estrutural, conhecido como porte, é uma característica de alta influência nos parâmetros produtivos e pode ser definida de forma qualitativa. O porte do animal influencia suas características produtivas, uma vez que aqueles de maior porte apresentam maiores pesos de terminação (Di Marco, 1998), maiores carcaças e menor quantidade de gordura intramuscular (Camfield et al., 1997; May et al., 1992).

Animais de grande porte têm maior potencial de ganho de peso e maturidade mais tardia, além de menor deposição de gordura na carcaça, maior consumo por unidade de peso e capacidade de retenção de proteína em relação à gordura (Di Marco, 1998). Apesar de esses animais requererem maior tempo de confinamento para atingir a condição de abate, seus pesos de abate e de carcaça aumentam com o aumento do porte (Dolezal, 1993).

Desta forma, realizou-se este experimento para avaliar as características de carcaça e a qualidade da carne de novilhos terminados em confinamento com dois pesos iniciais.

\section{Material e Métodos}

O experimento foi realizado no Laboratório de Bovinocultura do Departamento de Zootecnia da Universidade Federal de Santa Maria (UFSM), Rio Grande do Sul, a $53^{\circ} 08^{\prime}$ longitude Oeste e $29^{\circ} 68^{\prime}$ latitude Sul e $90 \mathrm{~m}$ de altitude.

Foram utilizados 12 novilhos castrados, 5/8 Nelore 3/8 Charolês, com média de 22 meses de idade (660 dias), contemporâneos e provenientes do rebanho experimental da UFSM. Os animais, filhos de vacas e touros do mesmo rebanho experimental, foram obtidos do cruzamento rotativo entre as raças Charolês e Nelore e permaneceram juntos, com mesmo manejo, do nascimento até o início do experimento. Aos 75 dias de idade, em média, os novilhos foram desmamados e mantidos em pastagem cultivada de inverno no primeiro inverno e em pastagem natural durante o verão seguinte.

Os animais foram terminados em confinamento e divididos em duas categorias: animais leves, com peso vivo (PV) inicial de $362,67 \mathrm{~kg}$, e animais pesados, com peso vivo inicial de $441,83 \mathrm{~kg}$. Os animais pesados foram mantidos durante 30 dias e os leves, 94 dias, no confinamento para atingir o peso pré-determinado de $500 \mathrm{~kg}$.

Durante o confinamento, os animais foram alimentados com silagem de milho e concentrado, relação volumoso:concentrado de 60:40, com base na matéria seca (MS) (Tabela 1). A dieta foi calculada segundo o NRC (1996) objetivando ganho de peso médio diário de $1,6 \mathrm{~kg}$ /animal com consumo de 2,5 kg de MS/100 kg de PV. Os animais receberam alimentação à vontade, duas vezes ao dia (8 e 17 h). A dieta continha 10,25\% de proteína bruta e 3,18 Mcal de energia digestível/ $\mathrm{kg}$ de $\mathrm{MS}$.

No início e fim do confinamento, os animais foram medidos utilizando-se fita métrica para determinação das alturas de garupa inicial e final e cálculo do porte dos animais, que varia de 1 a 10 , de modo que $1=$ animal de pequeno tamanho estrutural e $10=$ animal de grande tamanho estrutural, por meio da fórmula descrita por Di Marco (1998), em que altura é determinada em polegadas e a idade em dias: $\mathrm{F}=-11,548+0,487 \times$ altura $-0,0289 \times$ idade $+0,00001947$

$\times$ idade $^{2}+0,0000334 \times$ altura $\times$ idade

$\mathrm{O}$ abate foi realizado em frigorífico comercial, conforme fluxo normal de abate, após jejum de sólidos, durante 14 horas, e pesagem para obtenção do peso de fazenda (PF) dos animais. No final da linha de abate, as carcaças foram pesadas, para obtenção do peso de carcaça quente (PCQ), e mantidas 24 horas em câmara fria de $0 \mathrm{a} 4^{\circ} \mathrm{C}$ para posterior pesagem e obtenção do peso de carcaça fria (PCF).

Após o resfriamento, as carcaças foram divididas ao meio. Cada meia-carcaça esquerda foi dividida em traseiro especial, dianteiro com cinco costelas e costilhar.

Na meia-carcaça fria direita, foram feitas medições, com fita métrica, para obtenção das seguintes medidas: compri-

Tabela 1 - Composição da dieta, em porcentagem da matéria seca

\begin{tabular}{lc}
\hline Ingrediente & $\%$ \\
\hline Silagem de milho & 60,00 \\
Farelo de trigo & 28,24 \\
Sorgo grão & 10,07 \\
Uréia & 0,17 \\
Calcário calcítico & 1,02 \\
NaCl & 0,48 \\
Rumensin ${ }^{\circledR}$ & 0,0128 \\
\hline
\end{tabular}


mento de carcaça (bordo anterior do púbis ao bordo anterior medial da primeira costela); comprimento de perna (distância entre o bordo anterior do osso púbis e articulação tíbiotarsiana); espessura de coxão (medido entre a face lateral e a face medial da porção superior do coxão, com auxílio de um compasso); perímetro e comprimento de braço, determinados de acordo com Muller (1987). Após as medições, foi realizado um corte na altura da $12 \mathrm{a}$ e 13 a costelas, expondo o músculo Longissimus dorsi para medição da gordura de cobertura, tomando-se três leituras em volta do músculo e, a partir de sua média aritmética, obteve-se a espessura de gordura (EG), em milímetros (Müller, 1987). Neste mesmo músculo, também foram avaliados subjetivamente a cor $(1=$ escura e $5=$ vermelho viva $)$, a textura $(1=$ muito grosseira e $5=$ muito fina $)$ e o marmoreio $(1=$ traços menos; $5=$ leve; $8=$ pequena; $11=$ média $; 14=$ moderada; $18=$ abundante mais) (Müller, 1987).

Foi realizada a separação física de uma peça de músculo Longissimus dorsi, retirada entre a $10^{\mathrm{a}}$ e $12^{\mathrm{a}}$ costelas da carcaça esquerda, e posteriormente foram calculadas as quantidades de músculo, gordura e osso na carcaça, conforme metodologia utilizada por Hankis \& Howe (1946), adaptada por Muller(1973). A relação músculo:osso foi obtida pela divisão dos valores de músculo $(\mathrm{kg})$ pelos de osso $(\mathrm{kg})$ e a relação porção comestível:osso, pela soma dos valores de músculo $(\mathrm{kg})$ e gordura $(\mathrm{kg})$ dividida pelos valores de osso $(\mathrm{kg})$.

As amostras do músculo Longissimus dorsi foram embaladas em filme plástico e envoltas com papel pardo, identificadas e congeladas para posterior avaliação organoléptica da carne. As avaliações da carne foram realizadas no Laboratório de Carnes do Laboratório de Bovinocultura de Corte do Departamento de Zootecnia da UFSM por uma equipe de avaliadores treinados. Foram extraídos dois bifes de $2,5 \mathrm{~cm}$ de espessura (fatia A e B). Com a fatia A, obteve-se o peso do bife congelado em balança de precisão. Depois de descongelado em temperatura de resfriamento (entre 4 e $10^{\circ} \mathrm{C}$ ), o bife foi pesado para obtenção da quebra por descongelamento. Após seu cozimento, até que atingisse temperatura interna de $70^{\circ} \mathrm{C}$, a fatia foi novamente pesada para obtenção da quebra por cozimento. Após a pesagem, foram retiradas três amostras longitudinalmente às fibras musculares para determinação da maciez pelo aparelho Warner Bratzler Shear e obtenção da força de cizalhamento $\left(\mathrm{kgf} / \mathrm{cm}^{2}\right)$. A fatia B foi cozida nas mesmas condições da fatia A e, depois de avaliada por um painel de degustadores, foi analisada de forma subjetiva quanto à maciez $(1=$ extremamente dura e $9=$ extremamente macia $)$, palatabilidade $(1=$ sem sabor e $9=$ extremamente saborosa $)$ e suculência ( $1=$ sem suculência e $9=$ extremamente suculenta) por meio de mastigação.

O delineamento experimental foi o inteiramente casualizado, com dois tratamentos (leve ou pesado) e seis repetições. Os dados foram submetidos à análise de variância e comparados pelo teste F (SAS, 1997), a 5\% de significância, segundo o modelo estatístico:

$$
\mathrm{Y}=\mu+\mathrm{T}_{\mathrm{i}}+\mathrm{E}_{\mathrm{ij}}
$$

em que: $\mathrm{Y}=$ variáveis dependentes; $\mu=$ média dos tratamentos; $\mathrm{T}_{\mathrm{i}}=$ tratamentos, em que $\mathrm{i}=1$ (leve), 2 (pesado), $\mathrm{E}_{\mathrm{ij}}=$ erro aleatório.

\section{Resultados e Discussão}

Como o peso de abate $(511 \mathrm{~kg})$ foi determinado ao início do experimento, não diferiu entre os grupos (leves e pesados) (Tabela 2).

Não houve diferença no rendimento de carcaça fria (RCF), que foi de $55,42 \%$ para os animais leves e $54,42 \%$ para os animais pesados. Esperava-se que o rendimento de carcaça fria fosse menor nos animais pesados, uma vez que esta característica é altamente influenciada pela espessura de gordura na carcaça (Menezes et al., 2005; Kuss et al., 2005), que foi menor nos animais pesados. De acordo com Lawrie (1967), os músculos que possuem elevado conteúdo de gordura também possuem maior capacidade de retenção de água, fenômeno relacionado à possibilidade de que a gordura intramuscular relaxe a micro-estrutura, permitindo retenção de maior quantidade de água e diminuindo a perda por exsudação. Neste estudo esse efeito não ocorreu, pois os animais mais pesados ao início do confinamento apresentaram menor espessura de gordura subcutânea (EG) em comparação aos mais leves (Tabela 3 ) e não houve diferença no rendimento de carcaça nem significância no estudo de correlações entre estas duas variáveis (Tabela 6). Uma possível explicação para a falta de diferença para o rendimento de carcaça é a semelhança no peso de carcaça, que, segundo Euclides Filho et al. (1997), é altamente relacionado a suas características.

Os portes inicial $(3,65$ pontos $)$ e final $(5,52$ pontos $)$ dos animais leves foram menores (Tabela 3 ) que os dos animas pesados (4,82 e 6,14 pontos, respectivamente), o que era esperado, pois os animais foram recriados da mesma forma, sem restrição alimentar em nenhum dos grupos. $\mathrm{Na}$ metodologia utilizada no cálculo do porte, consideram-se a idade (que foi igual tanto para animais leves como pesados) e a altura. Portanto, animais mais pesados apresentaram maior porte em comparação aos leves, como conseqüência das maiores alturas inicial (134,67 vs $128,67 \mathrm{~cm})$ e final 
Tabela 2 - Peso de fazenda, pesos de carcaça quente e de carcaça fria, rendimentos de carcaça quente e de carcaça fria e quebra no resfriamento

\begin{tabular}{lrrrr}
\hline Característica & \multicolumn{2}{c}{ Peso inicial } & \multirow{2}{*}{ Erro-padrão } & P $>$ F \\
\cline { 2 - 4 } & Leve & Pesado & & \\
\hline Peso de fazenda, kg & 510,67 & 511,33 & 15,86 & 0,9769 \\
Peso de carcaça quente, kg & 289,52 & 285,00 & 10,02 & 0,7566 \\
Rendimento de carcaça & 56,64 & 55,76 & 0,68 & 0,3854 \\
quente, \% & & & & \\
Peso carcaça fria, kg & 283,42 & 278,17 & 10,08 & 0,7204 \\
Rendimento carcaça fria, \% & 55,42 & 54,42 & 0,67 & 0,3152 \\
Quebra no resfriamento, \% & 2,14 & 2,39 & 0,14 & 0,2466 \\
\hline
\end{tabular}

$(141,17$ vs 137,83$)$ dos animais pesados em relação aos leves.

Os animais de maior porte atingiram o peso de abate mais rapidamente, em virtude de seu maior potencial de produção de músculo, porém, as carcaças apresentaram grau de acabamento inferior. Di Marco (1998) admite que existem importantes diferenças metabólicas entre animais que não podem ser detectadas de forma direta pelo porte ou ganho de peso. $\mathrm{O}$ animal acumula quantidade de proteína tissular máxima (tecido magro), o que depende de fatores endógenos que determinam o crescimento. Assim, o maior porte aumenta o potencial de ganho de peso e retarda a maturidade, gerando animais com menor conteúdo de gordura e maior eficiência por unidade de tecido magro. Confirmando essas afirmações, Dolezal (1993) relata que animais de maior porte, em comparação aos de menor porte, requerem maior tempo de confinamento e atingem maiores pesos de abate e de carcaça para atingir o mesmo grau de acabamento.

Apesar de as alturas de garupa inicial e final serem maiores nos animais pesados, não foi observado maior comprimento de perna nesses animais, o que pode ser explicado pelo fato de a medida de comprimento de perna ser determinada pela distância entre o bordo anterior do osso púbis e a articulação tíbiotarsiana, não incluindo os ossos metatarsianos, onde possivelmente pudesse ocorrer alguma diferença.

Das características quantitativas da carcaça, apenas o comprimento do braço foi influenciado pelo peso dos animais no início do confinamento, em razão principalmente da maior altura dos animais com porte maior. A maturidade fisiológica é uma medida para identificar a idade animal por meio do estudo da ossificação das cartilagens presentes nas vértebras (processo espinhosos das vértebras torácicas e lombares e vértebras sacrais) (Müller, 1987). Animais de maior porte atingem a maturidade fisiológica em idade mais tardia e atingem peso de abate em menor tempo. Neste
Tabela 3 - Portes inicial e final, alturas inicial e final, conformação, maturidade fisiológica, comprimentos de carcaça e perna, espessura de coxão, comprimento e perímetro de braço e espessura de gordura

\begin{tabular}{lrrrr}
\hline Característica & \multicolumn{3}{c}{ Peso inicial } & \multirow{2}{*}{ Erro-padrão P $>$ F } \\
\cline { 2 - 3 } & Leve & Pesado & \\
\hline Frame inicial, pontos & 3,65 & 4,82 & 0,23 & 0,0049 \\
Frame final, pontos & 5,52 & 6,14 & 0,21 & 0,0581 \\
Altura inicial, cm & 128,67 & 134,67 & 1,30 & 0,0038 \\
Altura final, cm & 137,83 & 141,17 & 1,05 & 0,0479 \\
Conformação, pontos & 10,67 & 10,67 & 0,28 & 1,0000 \\
Maturidade fisiológica, pontos & 13,33 & 13,50 & 0,22 & 0,5995 \\
Comprimento de carcaça, cm & 129,00 & 130,50 & 1,64 & 0,5325 \\
Comprimento de perna, cm & 75,00 & 75,67 & 0,99 & 0,6456 \\
Espessura de coxão, cm & 27,33 & 27,00 & 0,74 & 0,7583 \\
Comprimento de braço, cm & 42,50 & 45,50 & 0,50 & 0,0017 \\
Perímetro de braço, cm & 38,50 & 40,00 & 0,65 & 0,1348 \\
Espessura de gordura, mm & 7,33 & 3,08 & 0,39 & 0,0001 \\
Espessura de gordura, \% & 2,62 & 1,11 & 0,17 & 0,0001
\end{tabular}

$\mathrm{P}<0,005$.

estudo, a diferença entre tempo de confinamento de 34 dias entre animais leves e pesados não foi suficiente $(\mathrm{P}>0,05)$ para alterar esta característica (Dolezal, 1993).

A espessura de gordura, expressa em milímetro e em porcentagem, foi influenciada pelos pesos iniciais de confinamento, uma vez que os animais do grupo leve apresentaram maior $(\mathrm{P}<0,05)$ valor. Esse resultado está relacionado principalmente ao maior tempo de terminação dos animais do grupo leve. Tecidos crescem e se desenvolvem cronologicamente em "ondas de crescimento" específicas. Segundo Owens (1993), certos tecidos crescem e atingem a maturidade antes de outros, uma vez que o crescimento começa com o tecido neural, depois o ósseo, o muscular e finalmente o tecido adiposo. Cada tecido desses desenvolve-se de forma precoce, intermediária ou tardia, dependendo de sua localização no corpo.

De acordo com Di Marco (1998), em animais de maior porte, a deposição de músculo é maior que a de gordura. Convencionalmente se aceita que o organismo tende a depositar ou ganhar uma quantidade de proteína pré-fixada de acordo com seu tamanho adulto ou porte, com quantidade de gordura que depende da quantidade e qualidade da alimentação. Conforme esse autor, existem moduladores do crescimento que controlam o metabolismo, a síntese e degradação protéica e o consumo para que o animal mantenha a retenção de tecido magro ou o peso dentro de certos limites. Assim, a quantidade de gordura aparentemente é uma conseqüência da interação desses moduladores de crescimento.

A maior precocidade dos animais de menor porte proporcionou-lhes maior deposição de gordura subcutânea em pesos corporais menores, o que certamente ocorreria em 
estágios mais avançados do grupo pesado. $\mathrm{O}$ valor de espessura de gordura obtido nos animais de menor porte foi semelhante ao reportado por Arboitte et al. (2004), que observaram que, à medida que se aproximam do tamanho adulto, os animais tendem a intensificar o processo de deposição de gordura. No mesmo estudo, os autores encontraram para espessura de gordura de 7,3 $\mathrm{mm}$ para os animais abatidos com $510 \mathrm{~kg}$.

O peso de costilhar foi maior nos animais leves $(38,33 \mathrm{~kg})$ em relação aos animais pesados (30,20 kg) (Tabela 4), o que pode estar relacionado à maior quantidade de gordura nas carcaças dos animais leves, principalmente gordura de cobertura. Arboitte et al. (2004), também utilizando animais $5 / 8 \mathrm{NC}$, observaram correlação entre espessura de gordura e costilhar de $0,71(\mathrm{P}=0,0009)$. Neste estudo a correlação entre estas características também teve valor semelhante $(\mathrm{r}=0,72 ; \mathrm{P}=0$,0077) (Tabela 6). Quando os valores dos cortes comerciais foram analisados em porcentagem, houve diferença estatística para os cortes traseiro e costilhar. Animais do grupo pesado apresentaram maior porcentagem de traseiro (52,64\%) em relação aos leves (49,39\%) e menor porcentagem de costilhar (10,95 vs $13,36 \%$, respectivamente). O traseiro é uma região comercialmente importante dos bovinos, pois apresenta os cortes de carne com maior valor comercial.

Os pesos de músculo, gordura e osso não foram afetados pelos pesos iniciais ao confinamento. Entretanto, quando estas características foram transformadas em porcentagem de peso vivo, animais de maior porte apresentaram maior quantidade de músculo $(65,37 \%)$ em relação aos de menor porte $(61,42 \%)$, o que pode ser explicado pelo fato de os animais de menor porte terem permanecido mais tempo em confinamento para atingir o mesmo peso de abate. Esses resultados corroboram os descritos por Luchiari Filho (2000) de que a medida de acabamento externo (espessura de gordura subcutânea) é a medida indireta de musculosidade da carcaça, haja vista a correlação negativa entre ambas. A correlação entre porcentagem de músculo e de gordura foi negativa e significativa $(r=-0,78 ; \mathrm{P}=0,0028)$ (Tabela 7), confirmando os resultados encontrados por Pacheco et al. (2005), que, em pesquisa com novilhos de diferentes idades, encontraram correlação de $-0,63$ entre essas características.

Não foi observado efeito do peso do início da terminação sobre as características da carne (Tabela 5). A textura é uma característica influenciada pela idade do animal, uma vez que, com o avançar da idade, a carne se torna mais grosseira. Os 64 dias a mais de confinamento não influenciaram $(\mathrm{P}>0,05)$ esta característica $(3,17$ vs 4,00 pontos, respectivamente, para animais leves e pesados).
Apesar de os animais leves terem apresentado maior $(\mathrm{P}<0,05)$ quantidade de gordura subcutânea, não foi observada diferença $(\mathrm{P}>0,05)$ para gordura intramuscular (marmoreio). Segundo Di Marco (1998), a gordura intramuscular está relacionada a certas propriedades que determinam a qualidade da carne, como o sabor, a suculência e, em alguns casos, a maciez. Esse autor considera as gorduras subcutânea e intramuscular mais importantes, pois são últimas a serem depositadas e as primeiras a serem movidas quando o animal passa por restrição alimentar.

Os animais mais leves apresentaram valores semelhantes $(\mathrm{P}>0,05)$ para maciez, tanto medida pelo WarnerBratzler Shear (3,95 kgf) quanto pelo painel (6,61 pontos), em relação aos animais pesados (4,50 kgf e 6,55 pontos).

Tabela 4 - Cortes comerciais e composição física da carcaça

\begin{tabular}{lrrrr}
\hline Característica & \multicolumn{2}{c}{ Peso inicial } & \multirow{2}{*}{ Erro-padrão $\mathrm{P}>\mathrm{F}$} \\
\cline { 2 - 3 } & \multicolumn{1}{c}{ Leve } & Pesado & & \\
\hline Traseiro, kg & 141,43 & 145,17 & 5,14 & 0,6185 \\
Dianteiro, kg & 106,60 & 100,40 & 3,65 & 0,2570 \\
Costilhar, kg & 38,33 & 30,20 & 1,85 & 0,0110 \\
Músculo, kg & 174,09 & 181,93 & 7,26 & 0,4630 \\
Gordura, kg & 65,84 & 54,60 & 4,47 & 0,1056 \\
Osso, kg & 43,77 & 42,53 & 3,91 & 0,8259 \\
Traseiro, \% & 49,39 & 52,64 & 0,49 & 0,0009 \\
Dianteiro, \% & 37,25 & 36,14 & 0,33 & 0,1051 \\
Costilhar, \% & 13,36 & 10,95 & 0,39 & 0,0015 \\
Músculo, \% & 61,42 & 65,37 & 1,20 & 0,0318 \\
Gordura, \% & 23,47 & 19,64 & 1,65 & 0,1329 \\
Osso, \% & 15,26 & 15,30 & 0,91 & 0,9765 \\
Relação músculo:osso & 4,12 & 4,28 & 0,20 & 0,5870 \\
Relação porção & 5,73 & 5,58 & 0,33 & 0,7502 \\
comestível:osso & & & & \\
\hline P<0,05. & & & & \\
\hline
\end{tabular}

Tabela 5 - Características qualitativas da carne de acordo com o peso inicial de confinamento

\begin{tabular}{|c|c|c|c|c|}
\hline \multirow[t]{2}{*}{ Característica } & \multicolumn{2}{|c|}{ Peso inicial } & \multirow[t]{2}{*}{ Erro-padrão } & \multirow[t]{2}{*}{ o $\quad \mathrm{P}>\mathrm{F}$} \\
\hline & Leve & Pesado & & \\
\hline $\begin{array}{l}\text { Quebra ao } \\
\text { descongelamento, \% }\end{array}$ & 0,11 & 0,10 & 0,01 & 0,2845 \\
\hline Quebra ao cozimento, $\%$ & 0,17 & 0,22 & 0,02 & 0,1407 \\
\hline Cor, pontos* & 3,83 & 3,83 & 0,25 & 1,000 \\
\hline Textura, pontos** & 3,17 & 4,00 & 0,34 & 0,1114 \\
\hline Marmoreio, pontos*** & 9,00 & 6,67 & 1,77 & 0,3724 \\
\hline Marmoreio, \% & 3,17 & 2,40 & 0,62 & 0,4003 \\
\hline Força de cizalhamento, kgf & 3,95 & 4,50 & 0,46 & 0,4148 \\
\hline Maciez, pontos & 6,61 & 6,55 & 0,34 & 0,9020 \\
\hline Palatabilidade, pontos & 7,00 & 7,27 & 0,22 & 0,4066 \\
\hline Suculência, pontos & 7,28 & 7,06 & 0,36 & 0,6671 \\
\hline \multicolumn{5}{|c|}{$\begin{array}{l}\mathrm{P}<0,05 . \\
\text { * Variação de } 1 \text { a } 5 \text {, em que } 1=\text { escura; } 3=\text { vermelho levemente escuro; } \\
5=\text { vermelho vivo. } \\
* * \text { Variação de } 1 \text { a } 5 \text {, em que } 1=\text { muito grosseira; } 3=\text { levemente grosseira; } \\
5=\text { muito fina. } \\
* * * \text { Variação de } 1 \text { a } 18 \text {, em que } 1 \text { a } 3=\operatorname{traços;~} 4 \text { a } 6=\text { leve. }\end{array}$} \\
\hline
\end{tabular}




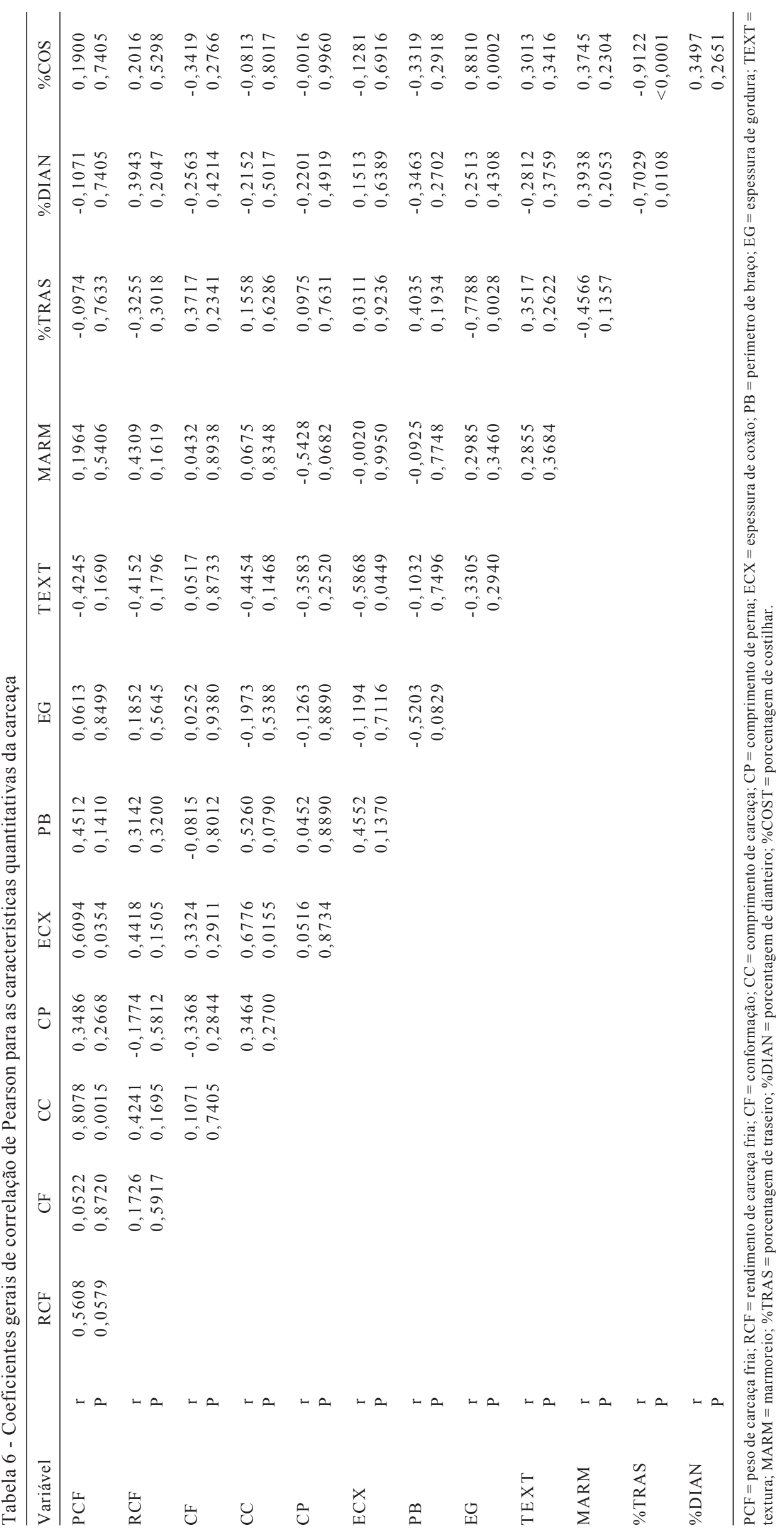




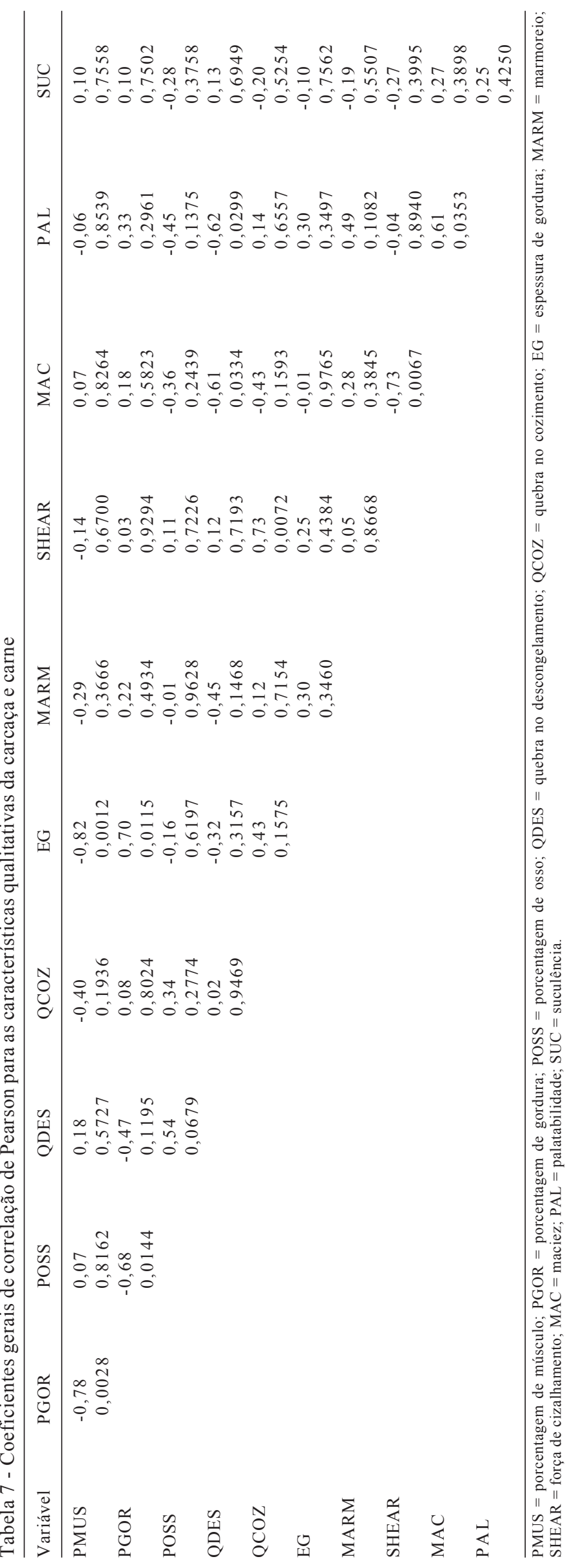

A suculência foi estatisticamente igual $(\mathrm{P}>0,05)$ para animais leves ( 7,28 ptos) e animais pesados ( 7,06 pontos). A suculência depende da sensação úmida durante os primeiros movimentos mastigatórios e, também de gordura que estimula a salivação (Lawrie, 1967). A sensação úmida pode ser influenciada pela perda de água durante o descongelamento e cocção, porém, na análise de correlações, somente houve correlação pequena, mas positiva, entre suculência e quebra ao descongelamento $(\mathrm{r}=0,13 ; \mathrm{P}=0,6949)$ (Tabela 7).

O sabor da carne depende da existência de gordura intramuscular (Lawrie, 1967; Di Marco, 1998) e da liberação de substâncias voláteis na carne (Lawrie, 1967). Neste contexto, o grau de marmoreio foi semelhante $(\mathrm{P}>0,05)$ para ambos os grupos de animais e, desta forma, a palatabilidade não foi influenciada pelo marmoreio $(7,0$ pontos para animais leves e 7,3 para animais pesados). Entretanto, a palatabilidade teve relação positiva com a maciez da carne $(\mathrm{r}=0,65 ; \mathrm{P}=0,053)$ (Tabela 7), comprovando que carnes mais macias possuem maior aceitabilidade pelos degustadores.

A escolha do tipo de animal a ser confinado é de extrema importância para o produtor, que poderá determinar menor tempo de terminação e menor custo com alimentação, ou animais com carcaças com maior acabamento e melhor aceitação do mercado. O mercado consumidor é quem determina a escolha mais adequada para ambas as partes, fato ocorrido quando confrontados os dados com a avaliação pelo Shear, uma vez que o aparelho, no momento da avaliação, só estima a força necessária para romper as fibras musculares, ou seja, não estima outras características que possam influenciar a maciez da carne.

\section{Conclusões}

Animais leves e de menor porte, ao início e final do período de terminação, permanecem por mais tempo em confinamento, o que resulta em carcaças com maior espessura de gordura subcutânea e maior peso de costilhar, além de menor porcentagem de traseiro e de músculo, em comparação a animais pesados e de maior porte nesta fase. $\mathrm{O}$ peso no início da terminação em confinamento não influencia as características organolépticas da carne de novilhos mestiços Nelore $\times$ Charolês.

\section{Literatura Citada}

ANUAlPeC Anuário da Pecuária Brasileira. São Paulo: Oesp Gráfica SA, 2006. 369p. 
ARBOITTE, M.Z.; RESTlE, J.; ALVES FILHO, D.C. et al. Características da carcaça de novilhos 5/8 Nelore 3/8-Charolês abatidos em diferentes estádios de desenvolvimento. Revista Brasileira de Zootecnia, v.33, n.4, p.969-977, 2004.

CAMFIELD, P.K.; BROWN JR., A.H.; LEWIS, P.K. et al. Effects of frame size and time-on feed on carcass characteristics, sensory attributes, and fatty acid profiles of steers. Journal of Animal Science, v.75, p.1837-1844, 1997.

DI MARCO, O.N. Crecimiento de vacunos para carne. 1.ed. Mar Del Plata: O. N. Di Marco, 1998. 246p.

DOLEZAL, H.G.; TATUM, J.D.; WILLIAMS JR., F.L. Effects of feeder cattle frame size, muscle thickness, and age class on days fed, weight, and carcass composition. Journal of Animal Science, v.71, p.2975-2985, 1993.

EUCLIDES FILHO, K.; EUCLIDES, V.P.B.; FIGUEIREDO, G.R. et al. Avaliação de animais Nelore e de seus mestiços com Charolês, Fleckvieh e Chianina, em três dietas. 2. Características de carcaça. Revista Brasileira de Zootecnia, v.26, n.1, p.73-79, 1997.

HANKINS, O.G.; HOWE, P.E. Estimation of the composition of beef carcasses and cuts. Washington, D.C.:USDA, 1946. 21p. (Technical Bulletin, 926).

KUSS, F.; RESTLE, J.; BRONDANI, I.L. et al. Composição física da carcaça e qualidade da carne de vacas de descarte de diferentes grupos genéticos terminadas em confinamento com distintos pesos. Revista Brasileira de Zootecnia, v.34, n.4, p.12851296, 2005

LAWRIE, R.A. Ciencia de la carne. 1.ed. Zaragoza: R.A. Lawrie, 1967. 380p
LUCHIARI FILHO, A. Pecuária da carne bovina. 1.ed. São Paulo: A. Luchiari Filho, 2000. 134p.

MAY, S.G.; MIES, W.L.; EDWARDS, J.W. et al. Beef carcass composition of slaughter cattle differing in frame size, muscle score, and external fatness. Journal of Animal Science, v.70, p.2431-2445, 1992.

MENEZES, L.F.G.; RESTLE, J.; VAZ, F.N. et al. Composição física da carcaça e qualidade da carne de novilhos de gerações avançadas do cruzamento alternado entre as raças Charolês e Nelore, terminados em confinamento. Revista Brasileira de Zootecnia, v.34, n.3, p.946-956, 2005.

MÜLLER, L. Técnicas para determinar la composición de la canal. Guadalajara: Memoria de la Asociación Latinoamericana de Producción Animal, 1973. 75p.

MÜLLER, L. Normas para avaliação de carcaças e concursos de carcaças de novilhos. 2.ed. Santa Maria: L. Müller, 1987. 31p.

NATIONAL RESEARCH COUNCIL - NRC. Nutrient requirements of domestic animals. 7.rev.ed. Washington, D.C.: National Academy Press, 1996. 242p.

OWENS, F.N.; DUBESKI, P.; HANSON, C.F. Factors that alter the growth and development of ruminants. Journal of Animal Science, v.71, p.3138-3150, 1993.

PACHECO, P.S.; RESTLE, J.; SILVA, J.H.S. et al. Composição física da carcaça e qualidade da carne de novilhos jovens e superjovens de diferentes grupos genéticos. Revista Brasileira de Zootecnia, v.34, n.5, p.1691-1703, 2005.

STATISTICAL ANALYSIS SYSTEMS - SAS. User's guide. Version 6, Cary: 1997. v.2, 1052p. 